\title{
Aneurysmal Bone Cyst of the Temporal Bone Presenting with Headache and Partial Facial Palsy
}

\author{
Stephanie N. Kletke ${ }^{1}$ Snezana Popovic ${ }^{2} \quad$ Almunder Algird ${ }^{3} \quad$ Abdullah Alobaid $^{3} \quad$ Kesava K. V. Reddy ${ }^{3}$
}

${ }^{1}$ Michael G. DeGroote School of Medicine, McMaster University,

Address for correspondence Stephanie N. Kletke, MD, Division of Hamilton, Ontario, Canada

2 Department of Pathology and Molecular Medicine, Neurosurgery, McMaster University, 644 Concession Street, Hamilton, McMaster University, Hamilton, Ontario, Canada

${ }^{3}$ Division of Neurosurgery, McMaster University, Hamilton, Ontario, Canada

J Neurol Surg Rep 2015;76:e18-e22.

\begin{abstract}
Keywords

- aneurysmal bone cyst

- dural tail sign

- skull base

- temporal bone

Background Aneurysmal bone cysts ( $A B C s$ ) are benign bony lesions that rarely affect the skull base. Very few cases of temporal bone $A B C$ s have been reported. We describe the first case of a temporal bone $A B C$ that was thought to be consistent with a meningioma based on preoperative magnetic resonance imaging (MRI) findings.

Clinical Presentation An otherwise healthy 23-year-old woman presented with a pulsatile noise in her left ear and a 4-week history of throbbing headache with nausea. There was no associated emesis, visual or auditory changes, or other neurologic features. Neurologic examination revealed a left lower motor neuron facial paresis. Computed tomography and MRI studies demonstrated a large lesion in the left middle cranial fossa skull base with erosion of the petrous temporal bone. Based on the presence of a "dural tail" on preoperative contrast-enhanced T1-weighted imaging, the lesion was interpreted to likely be consistent with a meningioma. An orbitozygomatic approach was utilized for surgical excision. Histopathologic evaluation was consistent with an $A B C$.

Conclusion Postoperatively the patient had improvement in the lower motor neuron facial paresis. It is important to consider $A B C$ in the differential diagnosis of intracranial lesions accompanied by the dural tail sign on MRI.
\end{abstract}

\section{Background}

Aneurysmal bone cyst $(A B C)$ is a benign bony lesion primarily located in long bones, flat bones, or vertebrae. ${ }^{1-4}$ Jaffe and Lichenstein first described the lesion in $1942 .^{5}$ Involvement of the skull is rare. There have been 43 reported cases of temporal bone $\mathrm{ABCs}$, only 15 of which had documented petrosal bone involvement. ${ }^{6-45}$ We present the first case of an $A B C$ of the middle cranial fossa skull base with erosion of the petrosal bone, accompanied by a

received

February 23, 2014 accepted after revision July 7, 2014

published online

January 16, 2015
DOI http://dx.doi.org/ 10.1055/s-0034-1390020. ISSN 2193-6366. "dural tail" on contrast-enhanced T1-weighted magnetic resonance imaging (MRI), a sign most classically associated with a meningioma.

\section{Clinical Presentation}

A 23-year-old right-hand-dominant woman presented with a 7-week history of a pulsatile noise in her left ear. She described the noise as more apparent at night. The patient also had a 4-week history of throbbing headache, with each
License terms

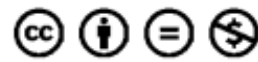

(c) 2015 Georg Thieme Verlag KG, Stuttgart - New York 


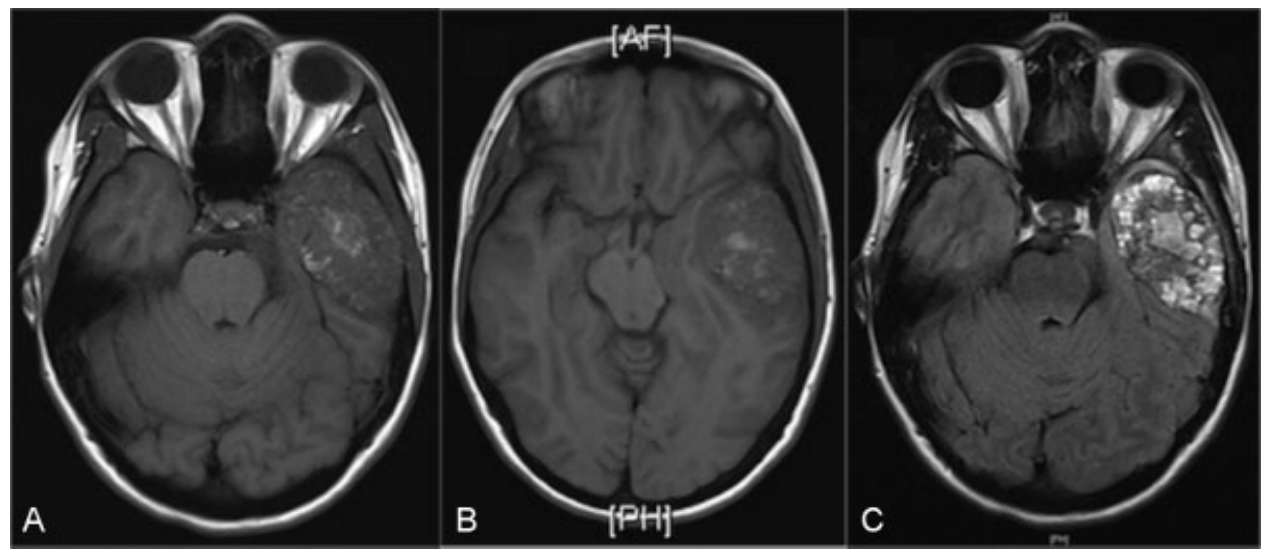

Fig. 1 Preoperative magnetic resonance imaging. (A) Axial T1-weighted noncontrast. (B) Axial T1-weighted noncontrast. (C) Axial fluidattenuated inversion recovery (FLAIR) noncontrast.

episode lasting $\sim 4$ to 5 hours. There was associated nausea but no vomiting. The patient denied any visual or other neurologic features associated with the headaches. She reported a 3-day history of worsening headache prior to presentation, for which she took Tramadol. The patient noted a change in her facial appearance and also appreciated impaired blinking on her left side. The patient's family had noticed that she was unable to raise her left eyebrow. She also had the sensation of her head spinning with postural changes.

Past medical history was significant for a remote sportsrelated concussion. The patient had some abdominal discomfort a few weeks prior to presentation, but no abnormality was detected at that time. She was otherwise healthy. On examination, there was evidence of a partial left lower motor neuron facial palsy. No other deficits were identified. The patient had improvement of her headache with dexamethasone.

Computed tomography (CT) and MRI studies demonstrated a large lesion in the left middle cranial fossa skull base with erosion of the petrous temporal bone. Preoperative MR images are demonstrated in -Figs. 1 and 2. Preoperative $\mathrm{CT}$ images are seen in - Figs. $\mathbf{3 A}$, 3B. The lesion was interpreted to likely be consistent with a meningioma because preoperative contrast-enhanced T1-weighted imaging demonstrated the "dural tail" sign frequently associated with meningioma.

The tumor was subsequently excised by a left-sided orbitozygomatic approach. The skull was found to be green in color with severe erosion of the outer table with tumor extending into the middle cranial fossa. Using intraoperative monitoring, the greater superficial petrosal nerve was identified and sectioned to prevent traction on the facial nerve. The tumor appeared to be insinuating into various foramina. The tumor resection was gross total. A cranioplasty was performed using titanium mesh. Histopathologic evaluation of the lesion revealed features of $A B C$, as demonstrated in - Fig. 4. Microscopic sections demonstrated multiple irregular spaces filled with blood surrounded by fibrous septa representing the cyst wall. The septa were composed of bland fibroblasts, occasional multinucleated giant cells, and capillaries. Osteoid formation was also noted. There were also areas of lacelike chondroid tissue and powdery calcifications.

Postoperatively, the patient had improvement in the lower motor neuron facial paresis and there was no worsening of her hearing. She had no other new deficits and was discharged home on the third postoperative day. Postoperative CT images are seen in - Fig. 3C, 3D.

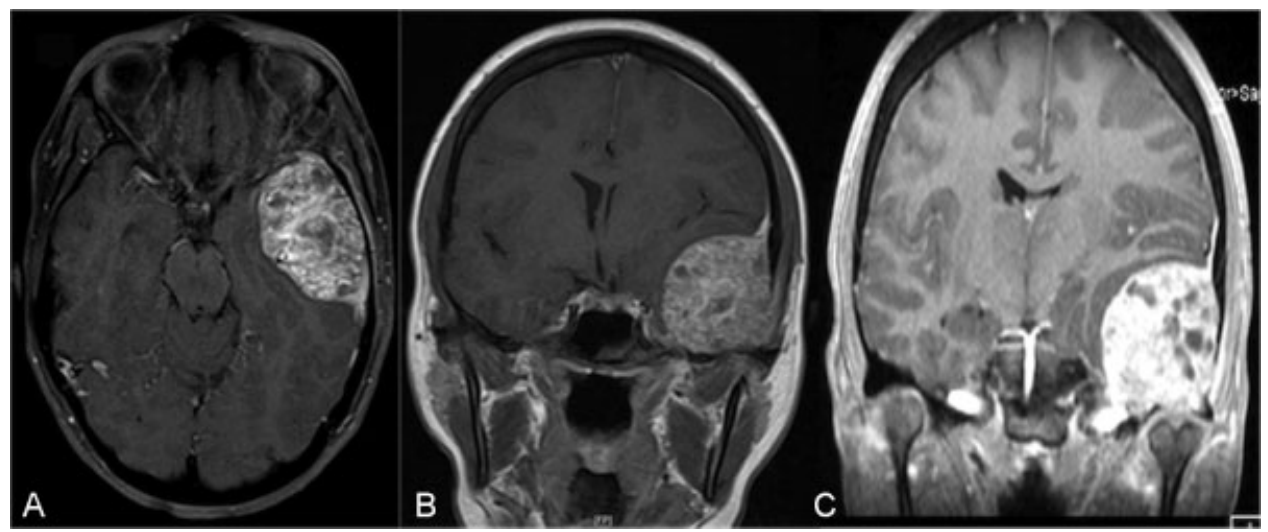

Fig. 2 Preoperative magnetic resonance imaging. (A) Axial T1-weighted with contrast. (B) Coronal T1-weighted with contrast. (C) Coronal magnetization-prepared rapid acquired gradient echo (MP-RAGE). 


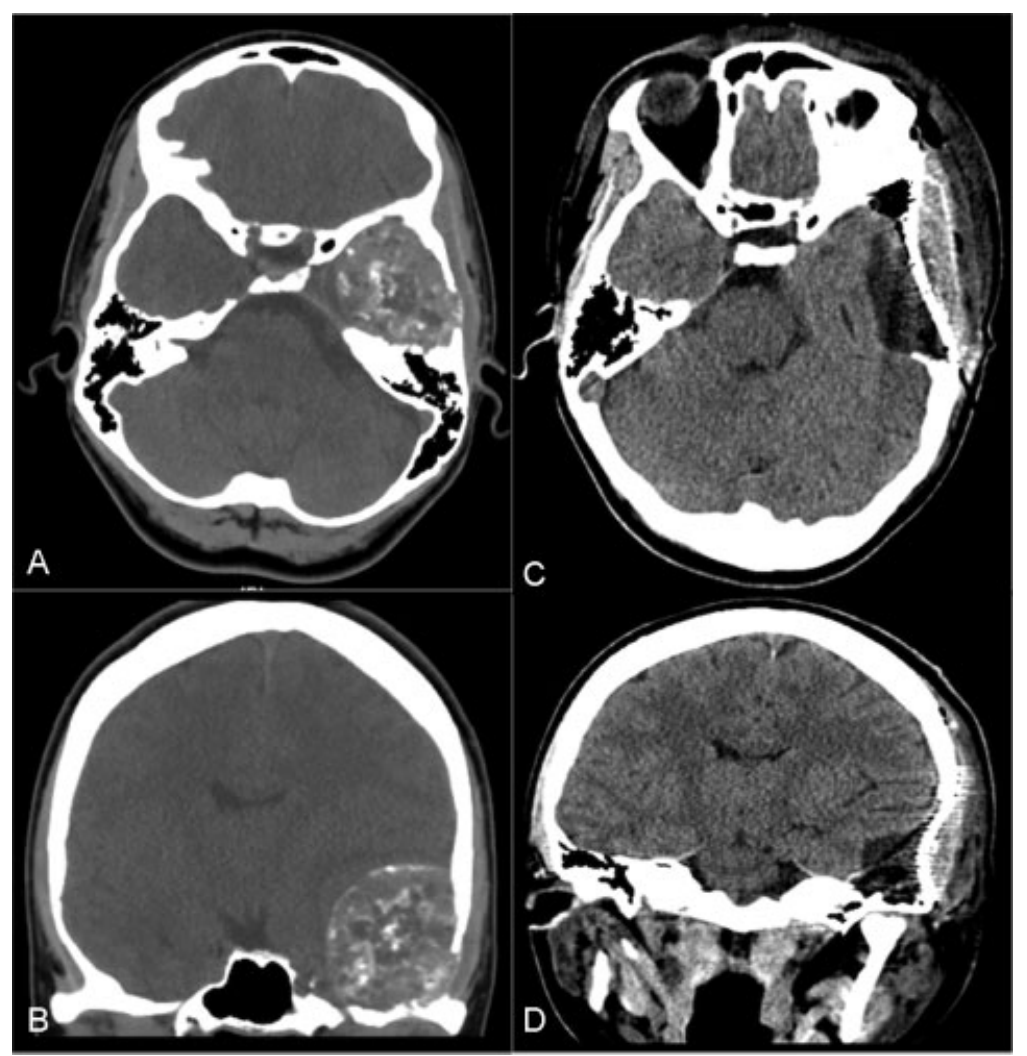

Fig. 3 Computed tomography images. (A) Preoperative axial. (B) Preoperative coronal. (C) Postoperative axial. (D) Postoperative coronal.

\section{Discussion}

ABC was first described by Jaffe and Lichenstein in 1942 as a "peculiar blood-containing cyst of large size." 5 It is considered a rare nonneoplastic expansile bony lesion. $\mathrm{ABC}$ was further described by Lichenstein as a "solitary, localized, expanded fibrous lesion with a dilated, plexiform vascular bed." ${ }^{46} \mathrm{~A}$ slight female predominance has been documented. ${ }^{1}$ Most patients present within the first 2 decades of life. ${ }^{1,4}$ The lesion most commonly involves the long bones, flat bones, and vertebrae. $^{1-4}$ Occurrence in the skull is quite rare, with the calvaria more commonly affected than the skull base. ABCs may be classified as primary or secondary bony lesions. In a previous report, $32 \%$ of $A B C$ s were found to arise from an accompanying benign primary bone lesion. ${ }^{1}$ The lesion in this case was a primary $\mathrm{ABC}$.

The underlying etiology of $A B C$ s is unknown. $A B C$ pathogenesis may be related to a vascular disturbance such as an arteriovenous communication. ${ }^{46}$ Biesecker et al $^{1}$ postulated that $\mathrm{ABC}$ are arteriovenous fistulae of bone produced from a primary bone lesion through hemodynamic interactions. Trauma has also been proposed as an underlying etiology, but several cases present with absence of preceding trauma. ${ }^{46}$ A presumed congenital $A B C$ of the temporal bone has also been described. ${ }^{24}$ Primary $A B C$ is associated with rearrangements of the USP6 (ubiquitin specific peptidase 6/Tre-2) gene. $^{47}$

A thorough literature review identified 43 reported cases of $\mathrm{ABC}$ of the temporal bone. ${ }^{6-45}$ Clinical presentations of the lesion in this area included localized swelling, $7,8,11-16,18,20,21,23,26,29-35,39,40,43,44 \quad$ hemifacial weakness or paralysis, ${ }^{6,10-12,18,23,27,28,33,36,38}$ hearing loss, ${ }^{9-12,23-25,27,28,36-40}$ headache, ${ }^{10-13,15,17,18,22,30,35,37,39}$ other signs of raised intracranial pressure, ${ }^{13,17,22}$ dysphagia, ${ }^{28}$ vertigo, ${ }^{9,22,23}$ tinnitus, ${ }^{9,25,35}$ facial paresthesias, ${ }^{38}$ diplopia, ${ }^{13}$ visual impairment, ${ }^{27,35}$ proptosis, ${ }^{14}$ otorrhea, ${ }^{33,39}$

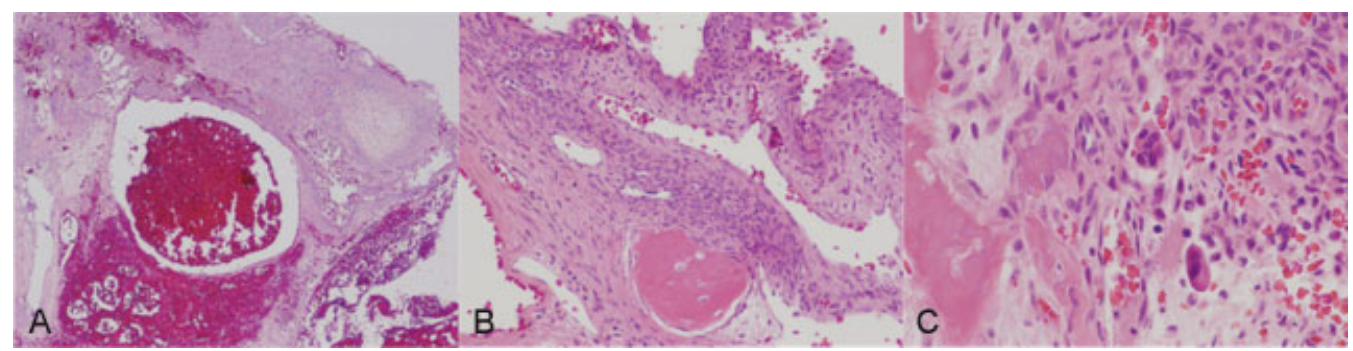

Fig. 4 Microscopic sections (hematoxylin and eosin stain) demonstrate features of aneurysmal bone cyst. (A) Blood-filled cystic cavity. (B) Fibrous tissue septa surrounding cavity with osteoid formation. (C) Presence of giant cells. 
recurrent bacterial meningitis, ${ }^{24}$ new-onset seizure activity, ${ }^{42}$ spontaneous intracerebral hemorrhage, ${ }^{19}$ and jugular foramen syndrome. ${ }^{6}$ Only 15 of these cases had documented petrous temporal bone involvement, 6,9,10,17,20,22-26,28,34-36,38 and approximately half of these lesions were localized primarily in the middle cranial fossa. The mean age of presentation was 20 years. The male-to-female ratio was $1.7: 1$. Of the cases that mentioned head trauma, $35 \%$ had a prior trauma history. Our patient was 23 years old and presented with headache, hemifacial paresis, and pulsatile tinnitus. There was a history of a remote sports-related concussion.

Radiographically, the $\mathrm{ABC}$ has been described as a ballooned expansile lesion limited peripherally by a thin shell of new periosteal bone formation, with a "soap bubble" appearance. ${ }^{5,46}$ CT findings reveal a heterogeneously enhancing multiloculated mass with varying densities and fluid-fluid levels in some cases. ${ }^{14}$ MRI demonstrates low to medium signal intensity on T1-weighted images. ${ }^{39,40}$ With gadolinium enhancement, cystic cavities are low intensity; internal septae are high intensity. ${ }^{37,39,40}$ The internal cysts are higher signal intensity with T2-weighted images, and they are surrounded by a lower intensity rim. ${ }^{26,39}$ Fluid-fluid levels may be present and may be better appreciated than with CT imaging. ${ }^{26,39,40}$

In the present case, the large lesion in the left middle cranial fossa skull base was initially interpreted to be consistent with a meningioma, based on the presence of the dural tail sign on gadolinium-enhanced T1-weighted MR images. The "dural tail" sign, a thickening of the dura on contrastenhanced T1-weighted MR images, was first described in continuity with meningiomas in $1989 .{ }^{48}$ Criteria for the dural tail were subsequently defined by Goldsher et al: (1) the tail is identified on at least two consecutive tumor sections, (2) it tapers from its greatest thickness adjacent to the tumor, and (3) the tail enhancement exceeds that of the tumor itself. ${ }^{49}$ Although initially believed to be pathognomonic of meningioma, the dural tail sign was subsequently reported in association with other cranial and spinal pathologies including primary and secondary central nervous system lymphoma, chloroma, multiple myeloma, glioblastoma multiforme, metastasis, medulloblastoma, pituitary adenoma, schwannoma, and others. ${ }^{50}$ In this case, histopathologic evaluation ultimately revealed features of $A B C$. To our knowledge, this is the first reported case of the MR dural tail sign in association with an $A B C$.

Histopathologic diagnosis of $A B C$ is based on the presence of blood-filled cystic spaces separated by fibrous septa. The fibrous septa are composed of fibroconnective tissue with occasional osteoclast-type giant cells and reactive new bone formation. ${ }^{47}$ The overlying bone can have erosions with cancellous bone replaced by fibrovascular tissue. ${ }^{46}$ Areas of hemorrhage are surrounded by fibroconnective tissue with areas of new bone formation. ${ }^{46}$ Numerous multinucleated giant cells may also be present, primarily near areas of hemorrhage. ${ }^{46}$

As in the case presented, complete surgical excision is the recommended treatment for $\mathrm{ABC}$ of the temporal bone. Cryosurgery was previously suggested. ${ }^{1}$ Radiotherapy has also been considered for large tumors, ${ }^{18}$ to reduce vascularity preoperatively $^{39}$ and to treat recurrent $\mathrm{ABC}$ of the temporal bone. $^{23}$ A dose of 30 to $36 \mathrm{~Gy}$ may be effective for this purpose. ${ }^{23}$ Preoperative embolization to decrease the vascular burden of the tumor and facilitate surgical removal has also been performed. ${ }^{38}$ Finally, a partially resected cranial base $A B C$ was successfully treated with repeated intralesional calcitonin injections using an Ommaya reservoir. ${ }^{20}$

\section{Conclusion}

$\mathrm{ABCs}$ of the temporal bone are rare, particularly involving the petrous portion. This is the first reported case of an $A B C$ of the temporal bone demonstrating a dural tail on contrast-enhanced T1-weighted MRI, a sign commonly associated with meningioma. There was improvement in the left partial lower motor neuron facial palsy following surgical excision via an orbitozygomatic approach. It is important to consider $A B C$ in the differential diagnosis of intracranial lesions accompanied by the dural tail sign on MR imaging.

\section{References}

1 Biesecker JL, Marcove RC, Huvos AG, Miké V. Aneurysmal bone cysts. A clinicopathologic study of 66 cases. Cancer 1970;26(3): 615-625

2 Lichtenstein L. Aneurysmal bone cyst; observations on fifty cases. J Bone Joint Surg Am 1957;39-A(4):873-882

3 Mankin HJ, Hornicek FJ, Ortiz-Cruz E, Villafuerte J, Gebhardt MC. Aneurysmal bone cyst: a review of 150 patients. J Clin Oncol 2005; 23(27):6756-6762

4 Vergel De Dios AM, Bond JR, Shives TC, McLeod RA, Unni KK. Aneurysmal bone cyst. A clinicopathologic study of 238 cases. Cancer 1992;69(12):2921-2931

5 Jaffe H, Lichtenstein L. Solitary unicameral bone cyst: with emphasis on the roentgen picture, the pathologic appearance, and the pathogenesis. Arch Surg 1942;44(6):1004-1025

6 Aghaghazvini L, Sedighi N, Karami P, Yeganeh O. Skull base aneurysmal bone cyst presented with foramen jugular syndrome and multi-osseous involvement. Iran J Radiol 2012; 9(3):157-160

7 Ait Benali S, Ibahioin K, Zamiati S, et al. Sphenotemporal aneurysmal bone cyst. A new case and review of the literature [in French]. Neurochirurgie 2000;46(1):50-53

8 Bhende YM, Kothare SN. Aneurysmal bone cyst; a case report. Ind Med Gaz 1950;85(12):544-546

9 Blanchard M, Abergel A, Williams MT, Ayache D. Aneurysmal bone cyst within fibrous dysplasia causing labyrinthine fistula. Otol Neurotol 2011;32(2):e11

10 Buxi TB, Sud S, Vohra R, Sud A, Singh S. Aneurysmal bone cyst of the temporal bone. Australas Radiol 2004;48(2):251-255

11 Cakirer S, Basak M, Celebi I, Kabukcuoglu F, Erdem Y. Aneurysmal bone cyst of the temporal bone. Curr Probl Diagn Radiol 2003; 32(4):169-175

12 Chalapati Rao KV, Rao BS, Reddy CP, Sundareshwar B, Reddy CR. Aneurysmal bone cyst of the skull. Case report. J Neurosurg 1977; 47(4):633-636

13 Chateil JF, Dousset V, Meyer P, et al. Cranial aneurysmal bone cysts presenting with raised intracranial pressure: report of two cases. Neuroradiology 1997;39(7):490-494

14 Chidambaram B, Santosh V, Balasubramaniam V. Aneurysmal bone cyst of the temporal bone. Childs Nerv Syst 2001;17(7): 411-414 
15 Gaillard J, Haguenauer JP, Dumolard P, Romanet P, Patricot L. Temporo-mastoid aneurysmal bone cyst [in French]. Rev Otoneuroophtalmol 1978;50(1):99-102

16 Haddad GF, Hambali F, Mufarrij A, Nassar A, Haddad FS. Concomitant fibrous dysplasia and aneurysmal bone cyst of the skull base. Case report and review of the literature. Pediatr Neurosurg 1998; 28(3):147-153

17 Ito H, Kizu O, Yamada K, Nishimura T. Secondary aneurysmal bone cyst derived from a giant-cell tumour of the skull base. Neuroradiology 2003;45(9):616-617

18 Jeremiah BS. Aneurysmal bone cyst of the temporal bone. J Int Coll Surg 1965;43:179-183

19 Keuskamp PA, Horoupian DS, Fein JM. Aneurysmal bone cyst of the temporal bone presenting as a spontaneous intracerebral hemorrhage: case report. Neurosurgery 1980;7(2):166-170

20 Khaldi M, Ben Hamouda K, Moussa M, Megdiche H, Boubaker A, Marrakchi M. Aneurysmal bone cyst of the cranial base treated by partial resection and calcitonin injection. A case report [in French]. Neurochirurgie 2006;52(1):57-62

21 Kowalik S, Janicki W. Aneurysmal temporal bone cyst [in Polish]. Otolaryngol Pol 1999;53(3):327-330

22 Kumar S, Retnam TM, Krishnamoorthy T, et al. Intracranial aneurysmal bone cyst manifesting as a cerebellar mass. Neurol India 2003;51(1):121-123

23 Kumar P, Singh S, Phadke RV, et al. Role of radiotherapy in a recurrent aneurysmal bone cyst of the temporal bone: case report. Neurosurgery 2006;58(3):E584; discussion E584

24 Lackmann GM, Töllner U. Aneurysmal cyst of the petrosal bone. Arch Dis Child 1993;69(2):241-242

25 Legent F, Lenne Y, Gayet M, et al. Aneurysmal cyst of the petrous bone. Apropos of a case [in French]. Ann Otolaryngol Chir Cervicofac 1988;105(8):591-596

26 Lippman CR, Jallo GI, Feghali JG, Jimenez E, Epstein F. Aneurysmal bone cyst of the temporal bone. Pediatr Neurosurg 1999;31(4): 219-223

27 Mima S, Taguchi Y, Sekino H, Inomata I. Case of aneurysmal bone cyst of the skull [in Japanese]. No Shinkei Geka 1984;12(7):825-831

28 Muzumdar DP, Goel A, Mistry R, Gujral S, Fattepurkar S. Postoperative cerebellar herniation in a large intrapetrous aneurysmal bone cyst. J Clin Neurosci 2004;11(5):534-537

29 Njock LR, Cartry F, Faucon B. Aneurysmal bone cyst of the tempora and zygomatic region. [in French]. Rev Laryngol Otol Rhinol (Bord) 2006;127(4):255-257

30 Paige ML, Chiu YT Jr, Christ M. Aneurysmal bone cyst of the temporal bone. Neuroradiology 1979;18(3):161-164

31 Park AH, Phillips J, Forte V. Aneurysmal bone cyst of the temporal bone. Otolaryngol Head Neck Surg 1999;120(4):606-610

32 Pedrosa R, Tizziani M, Raimúndez R, Vizcaíno JR, Ribeiro I. Aneurysmal bone cyst of the temporal bone in a 8 . year sold girl: case report [in Spanish]. Neurocirugia (Astur) 2010;21(2):132-137

33 Pellet W, Dufour H, Cannoni M, Dodero JC, Malca S, Choux R. Aneurysmal temporal bone cyst. Apropos of 2 new cases. [in French]. Neurochirurgie 1991;37(3):160-172
34 Purohit A, Chopra S, Sinha VD, Dharker SR. Aneurysmal bone cyst of the temporal bone: a case report. Neurol India 2002;50(4): 511-513

35 Rustiadji CE, Chunadi E, Koosnadi S, Kozlowski K. Post-traumatic aneurysmal bone cyst of the temporal bone. Radiol Med (Torino) 1989;78(4):386-387

36 Sabatini PR, Horenstein MG, Oliveri CV, Gacek RR. Aneurysmal bone cyst of the temporal bone associated with reversible hemifacial paralysis. Am J Otolaryngol 2005;26(4):261-264

37 Sawin PD, Muhonen MG, Sato Y, Smith RJ. Aneurysmal bone cyst of the temporal bone presenting as hearing loss in a child. Int J Pediatr Otorhinolaryngol 1995;33(3):275-284

38 Sayama CM, MacDonald JD. Aneurysmal bone cyst of the petrous bone: case presentation and review of the literature. Pediatr Neurosurg 2010;46(4):308-312

39 Shah GV, Doctor MR, Shah PS. Aneurysmal bone cyst of the temporal bone: MR findings. AJNR Am J Neuroradiol 1995; 16(4):763-766

40 Shimizu T, Ukai K, Hayashi T, Imanishi Y, Sakakura Y. Aneurysmal bone cyst of the temporal bone: magnetic resonance imaging as a valuable tool for preoperative diagnosis. Am J Otolaryngol 1998; 19(6):379-382

41 Smolka W, Lieger O, Balmer MC, Brekenfeld C, Iizuka T, Smolka K. Aneurysmal bone cyst of the tuberculum articulare of the temporomandibular joint: a case report. Quintessence Int 2008;39(8): 679-683

42 Stapleton CJ, Walcott BP, Linskey KR, Kahle KT, Nahed BV, Asaad WF. Temporal bone chondroblastoma with secondary aneurysmal bone cyst presenting as an intracranial mass with clinical seizure activity. J Clin Neurosci 2011;18(6):857-860

43 Tuna H, Karatas A, Yilmaz ER, Yagmurlu B, Erekul S. Aneurysmal bone cyst of the temporal bone: case report. Surg Neurol 2003; 60(6):571-574

44 Tzifa KT, Gan YC, Hockley AD, Wilson PS. Rapid enlargement of a bone cyst after biopsy. J R Soc Med 2002;95(7):360-361

45 Wachter W, Adler CP. Aneurysmal bone cyst of the temporal bone [in German]. Laryngol Rhinol Otol (Stuttg) 1984;63(12): 622-625

46 Lichtenstein L. Aneurysmal bone cyst: a pathological entity commonly mistaken for giant-cell tumour and occasionally for hemangioma and osteogenic sarcoma. Cancer 1950;3:279-289

47 Fletcher CDM, Bridge JA, Hogendoorn PCW, Mertens F. eds. WHO Classification of Tumours of Soft Tissue and Bone. Geneva, Switzerland: WHO Press; 2013

48 Wilms G, Lammens M, Marchal G, et al. Thickening of dura surrounding meningiomas: MR features. J Comput Assist Tomogr 1989;13(5):763-768

49 Goldsher D, Litt AW, Pinto RS, Bannon KR, Kricheff II. Dural "tail" associated with meningiomas on Gd-DTPA-enhanced MR images: characteristics, differential diagnostic value, and possible implications for treatment. Radiology 1990;176(2):447-450

50 Sotoudeh H, Yazdi HR. A review on dural tail sign. World J Radiol 2010;2(5):188-192 